Word count: 4473

\title{
Using Administrative Data for the Surveillance of Mood and Anxiety Disorders
}

\author{
Stephen Kisely * \\ Director, Queensland Centre for Health Data Services, University of Queensland, \\ Brisbane, Australia, and Professor, Departments of Psychiatry, Community Health \\ and Epidemiology, Dalhousie University, Halifax, Nova Scotia, Canada
}

\section{Elizabeth Lin}

Research Scientist, Health Systems Research and Consulting Unit, Centre for Addiction \& Mental Health, Toronto, Ontario, Canada

Charles Gilbert

Coordinator, Surveillance Division, Centre for Chronic Disease Prevention and Control, Public Health Agency of Canada, Halifax, Nova Scotia, Canada

\section{Mark Smith}

Associate Director, Repository, Manitoba Centre for Health Policy University of Manitoba, Canada

\section{Leslie-Anne Campbell}

Program Coordinator/Analyst, Health Outcomes Research Unit, Capital District Health Authority, Halifax, Nova Scotia, Canada

\section{Helen-Maria Vasiliadis}

Assistant Professor, Département des Sciences de la Santé Communautaire, University of Sherbrooke, Quebec, Canada

\footnotetext{
* Corresponding author. Queensland Centre for Health Data Services, Room 518(A), McGregor Building (No 64), The University of Queensland Brisbane, Qld 4072, AUSTRALIA Phone Number: 61 (07) 3365 51069; Fax Number: 61 (0)7 33821338

Email: s.kisely@uq.edu.au

Running Title: Surveillance of Mood and Anxiety disorder
} 


\section{ABSTRACT}

Objective: There is increasing interest in the use of administrative data for surveillance and research in Australia. We evaluated the usefulness of such data for the surveillance of mood and anxiety disorder using databases from the following Canadian provinces: British Columbia, Ontario, Quebec and Nova Scotia.

Method: A population-based record-linkage analysis using data from physician billings and hospital discharge abstracts, and community-based clinics using a casedefinition of ICD-9 diagnoses of 296.0-296.9, 311.0, and 300.0-300.9.

Results: The prevalence of treated mood and/or anxiety disorder was similar in Nova Scotia, British Columbia, and Ontario at approximately 10\%. The prevalence for Quebec was slightly lower at 8\%. Findings from the provinces showed consistency across age and sex despite variations in data coding. Women tended to show a higher prevalence overall of mood and anxiety disorder than men. However there was considerably more variation when treated anxiety (300.0-300.9) and mood disorders (296.0-296.9, 311.0) were considered separately. Prevalence increased steadily to middle age, declining in the 50s and 60s, and then increasing after 70 years of age.

Conclusions: Administrative data can provide a useful, reliable and economical source of information for the surveillance of treated mood and/or anxiety disorder. However, due to the lack of specificity in the diagnoses and data capture, it may be difficult to conduct surveillance of mood and anxiety disorders as separate entities. These findings may have implications for the surveillance of mood and anxiety disorders in Australia with the development of a national network for the extraction, linkage and analysis of administrative data.

Key words: surveillance; administrative data; mood disorder; anxiety; depression 


\section{INTRODUCTION}

Australia is one of few countries with comprehensive, high-quality, population data on many aspects of health and health care. With data linkage, much information could be drawn from routine data without the intrusion and cost of additional data collection.

In the area of mental health, Western Australia and Victoria provide examples of research using linked databases. These include studies of mortality and physical comorbidity such as cardiovascular disease and cancer in psychiatric patients, as well as contacts with the criminal justice system $[1-5]$. Up to now, research has been restricted to State-held data such hospital separations, community psychiatric contacts, cancer registries and vital statistics, but there are plans to include commonwealth data from Medicare and the Pharmaceutical Benefits Scheme. In addition, the commonwealth government has funded a network for the extraction, linkage and analysis of administrative data across Australia following the model of the Western Australian Data Linkage System (Figure 1). This Population Health Research Network (PHRN) is a national network with representation from all States and Territories that will use Australia's extensive health data to provide linkage across data sets to facilitate population health research (Figure 1). Commonwealth funding will flow through the University of Western Australia with matching funds from participating jurisdictions (Figure 1). One of the authors (SK) is the Director of the Queensland node at the Queensland Centre for Health data Services.

This paper describes how administrative data can be used for the surveillance of common psychiatric disorders using our experience of similar linked administrative databases in Canada. By surveillance, we mean the ongoing, systematic use of 
routinely collected population-based data to identify associations and predictors of health outcomes $[6,7]$

Although surveillance is commonly associated with communicable disease, administrative data are increasingly used for the surveillance of non-communicable disease such as mental illness, diabetes, arthritis, cancer, and circulatory disease [8]. In Canada, the National Diabetes and Other Chronic Diseases Surveillance System describes the occurrence, trends, and distribution of mental illness to support policy, programming and service delivery to those needing mental health services, and those at risk for mental illness [9].

An initial feasibility study focussed on overall psychiatric disorder (ICD9 codes 290-319 inclusive, or their ICD-10 or DSM-IV equivalents) [9]. This included organic brain syndromes, psychosis, non-psychotic disorders, adjustment disorders, personality disorders and developmental disorders. The prevalence of treated psychiatric disorder was similar in Nova Scotia, British Columbia, Alberta and Ontario at approximately 15\%, but slightly lower in Quebec (12\%). Findings from the provinces showed consistency across age and sex despite variations in data coding [9].

This study evaluated the usefulness of administrative data for the surveillance of more specific categories of mental illness. We selected mood and anxiety disorders because of their relative prevalence as indicated by other studies such as the Canadian Community Health Survey (1.2) [10]. We examined them both as a combined entity, and as separate categories.

We used the administrative databases from British Columbia, Ontario, Quebec and Nova Scotia. We combined mood and anxiety disorders as there is a large overlap in anxiety and depressive symptoms especially in primary care where the vast majority of psychiatric disorder is treated. Longitudinally, the course of anxiety 
disorders is often complicated by depression and vice versa [11]. In recognition of this overlap, ICD-10 includes a category of mixed anxiety and depressive disorder [12].

Support for an overlap between depression and anxiety also comes from twin studies where generalised anxiety and depression are genetically indistinguishable $[13,14]$. In addition, the two conditions have common personality traits, such as high levels of neuroticism [15].

\section{METHODS}

\section{Setting}

Canada (33 million) is a federation of 10 provinces and 3 territories with a tradition of publicly funded welfare, pensions and health care. Under the Canada Health Act, all Canadian residents are entitled to inpatient or outpatient care that is free at the point of delivery. Patients receive treatment at publicly-funded facilities, or are seen by private psychiatrists or general practitioners in the community who bill the provincial health plan of residence. However, provincial health plans do not cover visits to private psychologists or other mental health professionals in private practice. There are no private psychiatric beds. This study uses the routine administrative data that were collected in each province covering contacts at publicly funded facilities, as well as billings from medical specialists and general practitioners.

\section{Data sources}

This was a sample of four provinces with ready access to the following administrative databases:

- Physician billings data covering all fee-for-service claims including service date, physician type and associated diagnosis(ses). These are the equivalent of Medicare data in Australia. 
- Hospital discharge data (Med-Echo in Quebec, the Discharge Abstract

Database (DAD) in other provinces) including separation/admission dates and diagnoses

Coverage was province-wide except for Quebec, where it was limited to the Island of Montreal because of cost and time constraints. Table 1 shows the population size of each jurisdiction, as well as changes in population over the two relevant censuses (2001 and 2006). At over 18 million people, the study covered more than half the total population of Canada (Table 1). Records were included to 1995 where possible. Data were depersonalized or aggregated for privacy and confidentiality, and linked within each province through an encrypted unique identifier to further ensure anonymity. This unique identifier was derived from the provincial health card number to avoid the possibility of double-counting individuals who appeared in more than one provincial database. Irrespective of whether people appeared in one or more databases, they were counted once. We obtained ethics approval in each jurisdiction. We were unable to combine data across jurisdictions because of privacy legislation.

\section{Case Definition}

A case was defined as at least one physician visit, or discharge from any hospital, with one of the following codes as the most-responsible diagnosis: mood disorders (ICD-9 codes: 296.0-296.9 and 311.0) and anxiety disorders (ICD-9 codes: 300.0-300.9), or their ICD-10 or DSM-IV equivalents. In British Columbia, a patient with either condition can be coded with a single "50B” code for anxiety/depression. We included this code in our case definition. Rates were calculated annually. We also examined mood and anxiety disorders separately. 


\section{Analysis}

We tested the case definition by determining the prevalence of treated mood and/or anxiety disorder in each jurisdiction and comparing rates across age, sex, time and geography. In two provinces (Ontario and Quebec), we also undertook sensitivity analyses of the effect of excluding ICD-9 codes 300.8 (somatoform) and 300.9 (neurosis - not otherwise specified (NOS)) or their ICD10 equivalents.

The denominators in each province were derived from either the 2001 Canadian census or the provincial health insurance registry. As publicly funded health insurance covers almost the entire Canadian population both information sources cover the same population. The only exceptions are people covered by Federal arrangements for health care such as those in the military or federal correctional facilities. All findings were standardised by age and sex to the 2001 Canadian population. Age was reported in five-year groups based on the patient's age at year midpoint.

\section{RESULTS}

The data covered three to ten years depending on jurisdiction (Table 1). The prevalence of treated mood and/or anxiety disorder was similar in Nova Scotia, British Columbia and Ontario at approximately 10 - 11 \% (Table 1). The prevalence for Quebec was slightly lower at 8\% (Table 1). However there was considerably more variation among provinces when we considered mood and anxiety disorders separately (Table 1). In most provinces, the prevalence of obtaining services for anxiety was considerably greater than for mood disorder. However, in British Columbia the reverse was true (Table 1). One possible explanation was the large number of patients with code 50B for anxiety/depression that was not used in the 
other three provinces. Table 1 shows the effect of code 50B on the prevalence of anxiety and depressive disorders.

Women showed a higher prevalence of treated morbidity than men in all four jurisdictions. Figure 2 shows differences in prevalence by gender for treated mood and/or anxiety disorder in the most populous province (Ontario) where, coincidentally, data were available for the greatest number of years (1995-2004). The disparity in prevalence between genders was generally greatest for anxiety disorders. For instance in Nova Scotia, the annual rate for mood disorder in women was between 1.8 to $2.1 \%$ while the rate for men was consistently lower at around $1 \%$. In the case of anxiety, the rates for women ranged from 10.8 to $11.4 \%$, whereas the rates for men were from 5.8 to $6.1 \%$.

Figure 3 shows differences in prevalence by age for treated mood and/or anxiety disorder in the most populous province (Ontario) where, again, data were available for the greatest number of years (1995-2004). Prevalence increased steadily to middle age, declining in the 50s and 60s, and then increasing again after 70 years of age (Figure 3). There was no change in the pattern over the nine years covered by the data (Figure 3). The other provinces showed a similar pattern [16]. Excluding codes for somatoform disorders and neurosis - NOS made little difference to overall prevalence.

\section{DISCUSSION}

There are several information sources on the prevalence of mental illness including medical charts, electronic medical records, administrative records, and selfreport surveys $[17,18]$.

At the clinical level, medical charts and electronic medical records (EMRs) often contain detailed information but are both time consuming and expensive to 
retrieve and review [17]. Data quality may also vary [18]. At a population level, selfreport community surveys are more practical for estimating the prevalence of mental illness and are more representative of all cases, not just those presenting for treatment. Examples include the Canadian Community Health Survey Cycle (CCHS) 1.2 and the 2007 National Survey of Mental Health and Wellbeing in Australia, which both focused on mental health $[10,19]$. However, they are subject to recall bias, diminishing response rates, and, because they are expensive to undertake, are often conducted just once or repeated on an irregular, cross-sectional basis. Because of this, they are not suitable for the collection of longitudinal data. For instance, differences in methodology between the National Surveys of Mental Health and Wellbeing of 1997 and 2007 have made the comparison of results over time difficult [19]. Furthermore, surveys may miss people who are in remission at the time of interview, such as those taking antidepressants, if lifetime symptoms are not assessed [20].

Administrative data have several advantages over community surveys, or data derived from individual clinical settings. They provide accessible and timely longitudinal data for an entire jurisdiction at relatively little cost, and so can be useful for chronic disease surveillance [21, 22]. Their major weakness is that they were designed for billing, rather than surveillance, and so data accuracy may be compromised. Most data on accuracy concern inpatient morbidity [23, 24], rather than physician billings, where most encounters occur.

This study has shown the feasibility of using administrative data to measure the prevalence of treated mood and/or anxiety disorder by age, gender and time. Despite suspected variations in data coding, the results show acceptable uniformity across the provinces. Rates showed stability over time in spite of changes in population size over the period covered by the study. The rate of between 10 and $11 \%$ 
for combined mood and/or anxiety disorder is similar to the prevalence reported in the Stirling County Study, the longest longitudinal epidemiological study of psychiatric morbidity in Canada [11]. Quebec had a slightly lower prevalence possibly because the sample only included Montreal where psychologists, who were not captured in these data, play a greater role in treatment than in the other three provinces.

Our results are also consistent with findings for depression and anxiety from the Canadian Community Health Survey of 2002 [10]. However, the rates are lower than those reported in Australia where the the 2007 National Survey of Mental Health and Wellbeing reported a 12 month prevalence of $20 \%$ for anxiety and affective disorder [19]. The reasons for this are unclear and cannot entirely be explained by differences in methodology. For instance, both the Canadian Community Health Survey and the National Survey of Mental Health and Wellbeing are based on representative community samples and used the World Mental Health Survey Initiative version of the World Health Organization's Composite International Diagnostic Interview to estimate the prevalence of specific mental disorders [19, 25]. One reason for the discrepancy might be that one study used definitions and criteria of the World Health Organization's (WHO) International Classification of Diseases, Tenth Revision (ICD-10) while the other DSM-IV. Another might be that the 2007 National Survey of Mental Health and Wellbeing was designed to provide lifetime prevalence estimates for mental disorders [19]. Twelve month diagnoses were based on lifetime diagnosis and the presence of symptoms of that disorder in the 12 months prior to the survey interview rather than the full diagnostic criteria.

In contrast to our results for mood and anxiety disorders when combined, there was considerably more variation when the two disorders were considered separately. While the treated prevalence for anxiety in this study was similar to those from 
population surveys $[10,11]$, the rate for mood disorder was much lower. In addition, there was variation among provinces in the ratio of anxiety to mood disorder. In most provinces, treated anxiety disorder was twice as common as mood disorder reflecting findings from surveys $[10,11]$. However the reverse was true for British Columbia. Receipt of services for mood and anxiety disorder may be difficult to distinguish because of overlaps in coding (e.g. code 50B for anxiety/depression), and clinical features (e.g. presentations in primary care) [26]. An estimated 85\% of patients with mood disorder have symptoms of anxiety, and 58\% have a diagnosable anxiety disorder during their lifetime [27]. The prevalence of comorbid generalised anxiety and depression, the most common combination, has been reported in as high as $60 \%$ to $90 \%$ of patients with generalised anxiety in the community [28]. There is a twoway relationship as $50 \%$ of patients with anxiety also experience depression at some stage [11].

The relationship between anxiety and mood disorders has been controversial [11]. Some researchers believe that generalised anxiety and mood disorders are separate disorders and that when they occur together, this marks co-morbidity [29-32]. For instance generalised anxiety and depression are distinct neuro-physiologically with differences in REM latency [33]. The two conditions also share relatively few childhood risk factors [34]. Other researchers emphasise the difficulties of distinguishing between the two conditions [35-37]. In particular, generalised anxiety seems more closely related to mood than to panic or phobic disorders. Longitudinally, anxiety often both precedes and follows depression [11, 38-42]. It is not surprising therefore that this ambiguity is reflected in our administrative data.

Discrepancies between administrative and survey data can also be partly explained by different biases such as recall or recording bias and that they cover 
different, albeit overlapping, populations [43]. For example, surveys identify people with unmet need not included in administrative data [10]. In Canada, the CCHS1.2 reported that only $32 \%$ of those with mental disorders or substance use had talked to a health professional in the preceding 12 months [10]. As in a previous study of overall psychiatric morbidity using administrative data, the prevalence of mood and/or anxiety disorder did not decline with increasing age in contrast to the prevalence in many surveys where it does [10]. Again, this may be due to recall or recording bias and different sampling frames. For instance, older people may present more commonly with somatic symptoms of common mental disorders, and be less likely to admit to psychiatric care in a survey.

Administrative data have limitations including recording bias, especially for diagnosis [9]. We emphasised overall mood and anxiety disorder rather than specific mood or anxiety disorders to minimise this. Administrative data only include treated mood and anxiety disorder captured through physician billings or inpatient data. However other work has shown that when data on visits to other disciplines in publicly-funded outpatient facilities are available, they make little difference to the treated prevalence rate [9]. We had most access to data from Ontario. However, with a population of 11.5 million, this was by far the largest jurisdiction covered by this study compared to a combined total from all the other jurisdictions of only 6.6 million. Finally, this was a sample of only four provinces, and the Quebec sample was restricted to Montreal.

These findings suggest that administrative data from hospital morbidity and physician billings can be used for surveillance of the prevalence of treated mood and/or anxiety disorder. These data can complement clinical records and community surveys. Such a surveillance system can provide longitudinal data at little cost for 
health service provision and planning.

However, the surveillance of mood and anxiety disorders as separate entities may be difficult due to lack of specificity in the diagnoses and data capture. A combined measure is therefore recommended for surveillance.

The Population Health Research Network (PHRN) in Australia offers the potential for a similar platform for surveillance and research. Unlike Canada, it will be possible to link anonymised databases across Australia through the use of robust protocols to preserve confidentiality [44].

\section{Funding and Support}

The Public Health Agency of Canada funded the data extraction and linkage used in this research. Steve Kisely, Elizabeth Lin, Mark Smith, Leslie Anne Campbell, and Helen Vasiliadis report no conflict of interest. Charles Gilbert is employed by the Public Health Agency of Canada

\section{Acknowledgments}

The authors wish to thank Wayne Jones, University of British Columbia for the data from British Columbia. The data from Quebec were made available by Montreal's Agency for Health and Social Services (Agence de la santé et des services sociaux de Montréal) through the Access to Information Agency (Commission d'Accéss à I Information); we wish particularly to thank Mike Benigeri from the Agency. Ontario data were accessed and analysed through the Institute of Clinical Evaluative Sciences (ICES). ICES is supported in part by a grant from the Ontario Ministry of Health and Long-Term Care. The data from Nova Scotia were made available by the Population Health Research Unit (PHRU) within Dalhousie University’s Department of Community Health and Epidemiology. The Province of Nova Scotia supplies the PHRU with complete Medicare and hospital files suitable for research purposes. The opinions, results and conclusions are those of the authors, and no endorsement by any of the relevant data sources or provincial governments is intended, or should be inferred. 


\section{References}

1. Lawrence D, Holman CDJ, Jablensky AV. Preventable Physical Illness in People with Mental Illness. Perth: The University of Western Australia, 2000.

2. Lawrence D, Jablensky AV, Holman CD, Pinder TJ. Mortality in Western Australian psychiatric patients. Soc Psychiatry Psychiatr Epidemiol. 2000; $35: 341-7$

3. Lawrence D, Holman CDJ, Jablensky AV, Threlfall TJ, Fuller SA. Excess cancer mortality in Western Australian psychiatric patients due to higher case fatality rates. Acta Psychiatr Scand. 2000; 101:382-388.

4. Kisely S, Preston N, Xiao J Assessing the impact of compulsory community treatment on admission rates. A survival analysis using linked mental health and offender databases. Br J Psychiatry. 2004; 184: 432-8.

5. Segal SP, Burgess PM. Effect of conditional release from hospitalization on mortality risk. Psychiatr Serv. 2006; 57:1607-13.

6. Last J. Dicionary of Epidemiology. A dictionary of epidemiology. Oxford: Oxford University Press, 1988

7. Choi BC. Perspectives on epidemiological surveillance in the $21^{\text {st }}$ century. Chron Dis Canada 1998;19:145-51.

8. Chronic Non-Communicable Disease Infostructure Sub-Group for the Health Surveillance Working Group. National surveillance networks for chronic disease in canada charting a path forward. Ottawa: Health Canada, 2001; [cited 2008 November 28]. Available from URL: http://cc.msnscache.com/ cache.aspx?q=national+diabetes+and+other+chronic+diseases+surveillance+syste 
$\mathrm{m}+\mathrm{i} \& \mathrm{~d}=74492033834047 \& \mathrm{mkt}=$ en-AU\&setlang=en-

AU\&w=22b57676,65657dc9

9. Kisely S Lin E, Lesage A, Gilbert C, Smith M, Campbell LA, Vasiliadis H. Use of Administrative Data for the Surveillance of Mental Disorders in Five Provinces Can J Psychiatry 2009 (In press)

10. Statistics Canada. Canadian Community Health Survey Cycle 1.2. Any measured disorder or substance dependence, by age group and sex, household population aged 15 and over, Canada excluding territories, 2002; [cited 2008 November 28]. Available from URL: http://www.statcan.gc.ca/pub/82-617-x/4067678-eng.htm

11. Murphy JM, Horton NJ, Laird NM, Monson RR, Sobol AM, Leighton AH. Anxiety and depression: a 40-year perspective on relationships regarding prevalence, distribution, and comorbidity. Acta Psychiatr Scand. 2004; 109:35575.

12. Starcevic V. Anxiety disorders no more? Australas Psychiatry 2008; 16:5,317-321

13. Roy MA, Neale MC, Pedersen NL, Mathe AA, Kendler KS. A twin study of generalized anxiety disorder and major depression. Psychol Med 1995; 25: 10371049.

14. Kendler KS, Gardner CO, Gatz M, Pedersen NL. The sources of co-morbidity between major depression and generalized anxiety disorder in a Swedish national twin sample. Psychol Med 2007; 37:453-462.

15. Watson D, Gamez W, Simms LJ. Basic dimensions of temperament and their relation to anxiety and depression: a symptom-based perspective. $J$ Res Pers 2005; 
39: 46-66.

16. Gilbert C. Using Administrative Data for the Surveillance of Mood and Anxiety Disorders. Ottawa: Surveillance Division, Centre for Chronic Disease Prevention and Control, Public Health Agency of Canada; 2009 (In press).

17. Rozario PA, Morrow-Howell N, Proctor E. Comparing the congruency of selfreport and provider records of depressed elders’ service use by provider type. Med Care 2004; 42:952-9.

18. Ritter PL, Stewart AL, Kaymaz H, Sobel DS, Block DA, Lorig KR. Self-reports of health care utilization compared to provider records. J Clin Epidemiol 2001; 54:136-41.

19. Australian Bureau of Statistics. National survey of mental health and well being : summary of results, 2007. Canberra: Australian Bureau of Statistics, 2008. [cited 2009 April 22] Available from URL: http://www.ausstats.abs.gov.au/ ausstats/ subscriber.nsf/0/6AE6DA447F985FC2CA2574EA00122BD6/\$File/43260_2007. pdf.

20. Beck CA, Patten SB. Adjustment of antidepressant utilization rates to account for major depression in remission. Comp Psychiatry 2004; 45:268-74.

21. National Diabetes Surveillance System. Responding to the challenge of diabetes in Canada. First report of the National Diabetes Surveillance System. Ottawa: Health Canada; 2003. [cited 2007 July 24]. Available from URL: : www.phacaspc.gc.ca/ccdpc-cpcmc/ndss-snsd/english/ pubs_reports/pdf/WEB_NDSS_English_Report-nocover.pdf . 
22. Gilbert C, Jones W, Schopflocher D, et al. Use of Provincial Administrative Data for Surveillance of Mental Disorders: Feasibility Study. Ottawa: Surveillance Division, Centre for Chronic Disease Prevention and Control, Public Health Agency of Canada; 2007.

23. Ontario Hospital Association, Ontario Ministry of Health, Hospital Medical Records Institute. Report of the Ontario Data Quality Reabstracting Study. Ontario: Ontario Hospital Association; 1991.

24. Williams JI, Young W. Inventory of studies on the accuracy of Canadian health administrative databases. Toronto: Institute for Clinical Evaluative Sciences in Ontario; 1996.

25. Gravel R, Béland Y. The Canadian Community Health Survey: mental health and well-being. Can J Psychiatry. 2005; 50:573-9

26. Devane CL, Chiao E, Franklin M, Kruep EJ. Anxiety disorders in the 21st century: status, challenges, opportunities, and comorbidity with depression. Am J Manag Care. 2005; 11(12 Suppl):S344-53.

27. Lenze EJ, Mulsant BH, Shear MK, et al. Comorbid anxiety disorders in depressed elderly patients. Am J Psychiatry. 2000; 157:722-728.

28. Flint A. Generalized anxiety disorder in elderly patients: epidemiology, diagnosis and treatment options. Drugs Aging. 2005; 22:101-114.

29. Sartorius N, Üstün B, Lecrubier Y, Wittchen HU. Depression comorbid with anxiety: results from the WHO study on psychological disorders in primary health care. In: Wittchen HU, ed. Comorbidity of mood disorders. Br J Psychiatry 1996; 
168 ( suppl. 30 ):38-43

30. Kessler RC, Dupont RL, Berglund P, Wittchen HU. Impairment in pure and comorbid generalized anxiety disorder and major depression in 12 months in two national surveys. Am J Psychiatry 1999; 156: 1915-1923.

31. Wittchen HU, Hoyer J. Generalized anxiety disorder: nature and course. J Clin Psychiatry 2001; 62: 15-19.

32. Hunt C, Issakidis C, Andrews G. DSM-IV generalized anxiety disorder in the Australian National Survey of Mental Health and Well-Being. Psychol Med 2002; 32: 649-659.

33. Papadimitriou GN, Kerkhofs M, Kempenaers C, Mendlewicz J. EEG sleep studies in patients with generalized anxiety disorder. Psychiatry Res 1988; 26:183-190.

34. Moffitt TE, Caspi A, Harrington $\mathrm{H}$ et al. Generalized anxiety disorder and depression: childhood risk factors in a birth cohort followed to age 32. Psychol Med 2007; 37:441-452.

35. Angst J, Dobler-Mikola A. The Zurich Study: VI. A continuum from depression to anxiety disorders. Eur Arch Psychiatry Neurol Sci 1985; 235:179-186.

36. Eaton WW, Ritter C. Distinguishing anxiety and depression with field survey data. Psychol Med 1988; 18:155-166.

37. Krueger RF. The structure of common mental disorders. Arch Gen Psychiatry 1999; 56:921-926.

38. Parker G, Hadzi-Pavlovic D. Is any female preponderance in depression 
secondary to a primary female preponderance in anxiety disorders? Acta Psychiatr Scand 2001; 103 252-256.

39. Stein MB, Fuetsch M, Müller N, Höfler M, Lieb R, Wittchen HU. Social anxiety disorder and the risk of depression: a prospective community study of adolescents and young adults. Arch Gen Psychiatry 2001; 58:251-256.

40. Parker G, Wilhelm K, Mitchell P, Austin MP, Roussos J, Gladstone G. The influence of anxiety as a risk to early onset major depression. J Affect Disord 1999; 52:11-17.

41. Wittchen HU, Hoyer J, Friis R. Generalized anxiety disorder: a risk factor for depression? Int J Methods Psychiatr Res 2001; 10:52-57.

42. Breslau N, Schultz L, Peterson E. Sex differences in depression: a role for preexisting anxiety. Psychiatry Res 1995; 58:1-12

43. Rhodes AE, Lin E, Mustard CA. Self-reported use of mental health services vs. administrative records. Should we care? Int J Methods Psychiatr Res 2002; 11:125-33.

44. Kelman CW, Bass AJ, Holman CD. Research use of linked health data--a best practice protocol. Aust N Z J Public Health. 2002; 26:251-5. 


\begin{tabular}{|c|c|c|c|c|c|c|c|c|c|}
\hline Province & $\begin{array}{l}\text { Years of } \\
\text { data }\end{array}$ & $\begin{array}{l}\text { Population } \\
\text { size } \\
(2001 \\
\text { census) }{ }^{\text {c }}\end{array}$ & $\begin{array}{l}\text { Provincial } \\
\% \text { change } \\
\text { in } \\
\text { population } \\
(1996- \\
2001)^{\mathrm{c}}\end{array}$ & $\begin{array}{l}\text { Provincial } \\
\% \text { change } \\
\text { in } \\
\text { population } \\
(2001- \\
2006)^{\mathrm{c}}\end{array}$ & $\begin{array}{l}\text { Mood } \\
\text { Disorder } \\
\text { (Percentage) }\end{array}$ & $\begin{array}{l}\text { Anxiety } \\
\text { Disorder } \\
\text { (Percentage) }\end{array}$ & $\begin{array}{l}\text { 50B } \\
\text { Anxiety/ } \\
\text { depression } \\
\text { (Percentage) }\end{array}$ & $\begin{array}{l}\text { Mood } \\
\text { Disorder or } \\
\text { Anxiety } \\
\text { Disorder or } \\
\text { both } \\
\text { (Percentage) }\end{array}$ & $\begin{array}{c}\text { Range in } \\
\text { Annual } \\
\text { Prevalence } \\
\text { Rates } \\
\text { (Percentage) }\end{array}$ \\
\hline Ontario & $1995-2004$ & $11,410,146$ & 1.4 & 4.3 & 0.5 & 10.5 & - & 10.7 & 10.5 to 11.2 \\
\hline Quebec (Montreal) $^{\mathrm{a}}$ & $2002-2004$ & $1,812,723$ & 6.1 & 6.6 & 2.9 & 6.6 & - & 8.4 & 8.2 to 8.6 \\
\hline Nova Scotia & $2000-2004$ & 908,007 & -0.1 & 0.6 & 1.6 & 8.6 & - & 9.9 & 9.2 to 9.8 \\
\hline $\begin{array}{l}\text { British Columbia } \\
\text { Without code 50B } \\
\text { With code } 50 B^{b}\end{array}$ & 1996-2002 & $3,907,738$ & 4.9 & 5.3 & $\begin{array}{l}9.4 \\
5.3\end{array}$ & $\begin{array}{l}3.6 \\
3.6\end{array}$ & $\begin{array}{c}- \\
5.0\end{array}$ & $\begin{array}{l}11.4 \\
11.5\end{array}$ & $\begin{array}{c}10.9 \text { to } 12.6 \\
-\end{array}$ \\
\hline
\end{tabular}

\footnotetext{
a Quebec data were from Montreal only.

b 2001 data

c Source: Statistics Canada
} 
Figure 1: Australia's Population Health Research Network

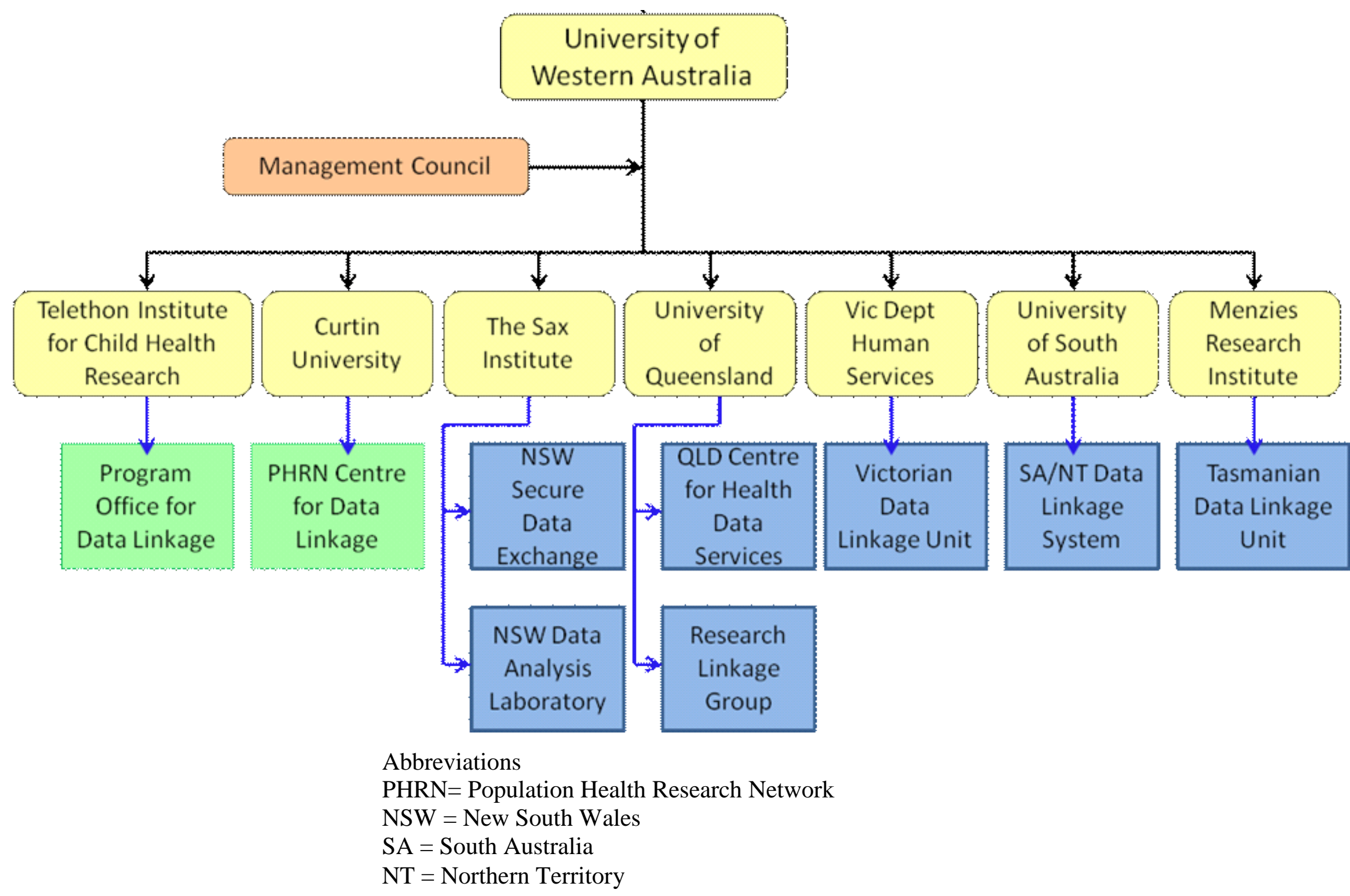


Figure 2: Percentage Prevalence of Accessing Services for Mental Illness for Anxiety and/or Mood disorders by gender by year for Ontario (1995 - 2004)

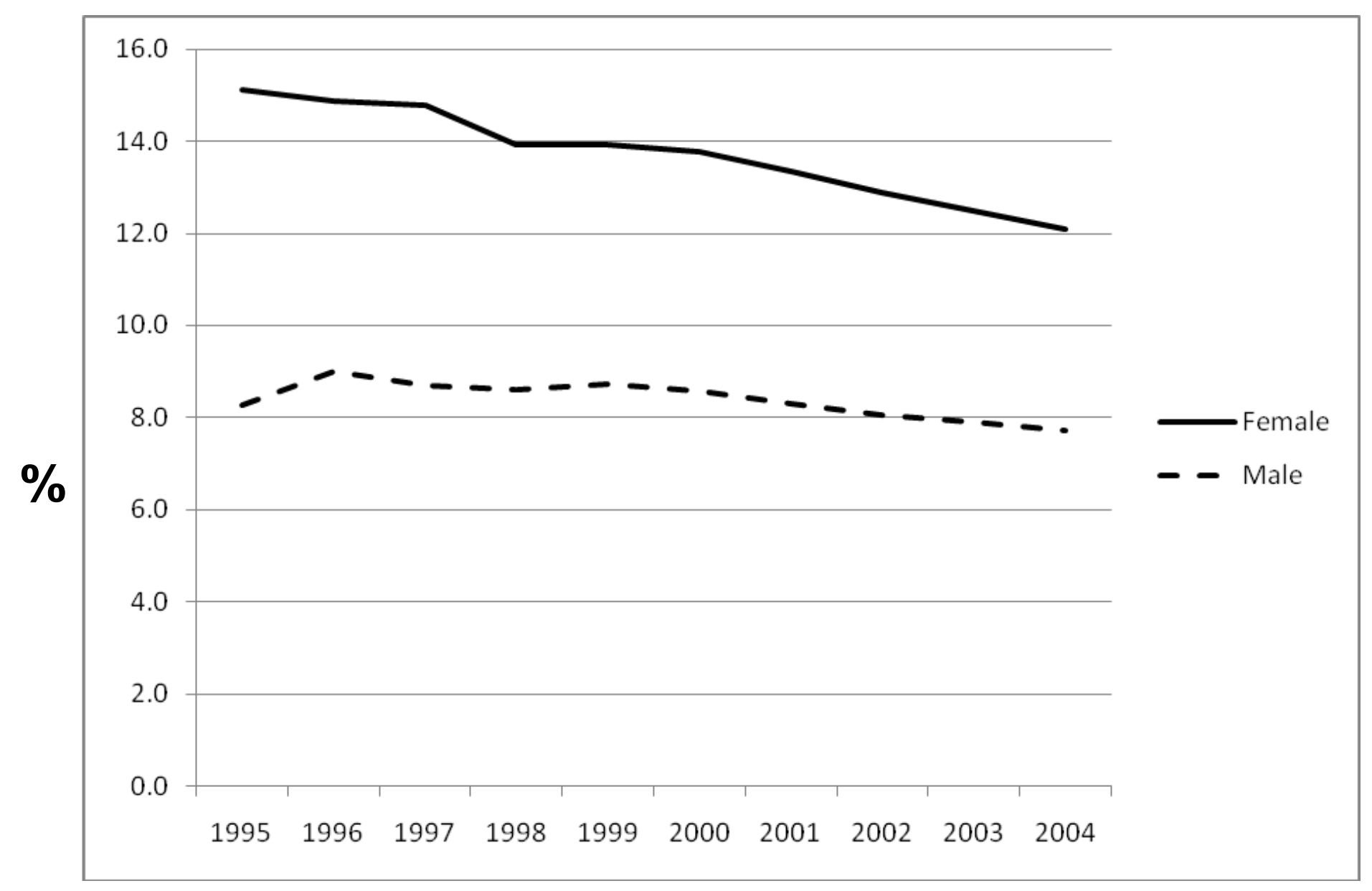


Figure 3: Mental IIIness for Anxiety and/or Mood disorders by age group by year for Ontario (1995 - 2004)

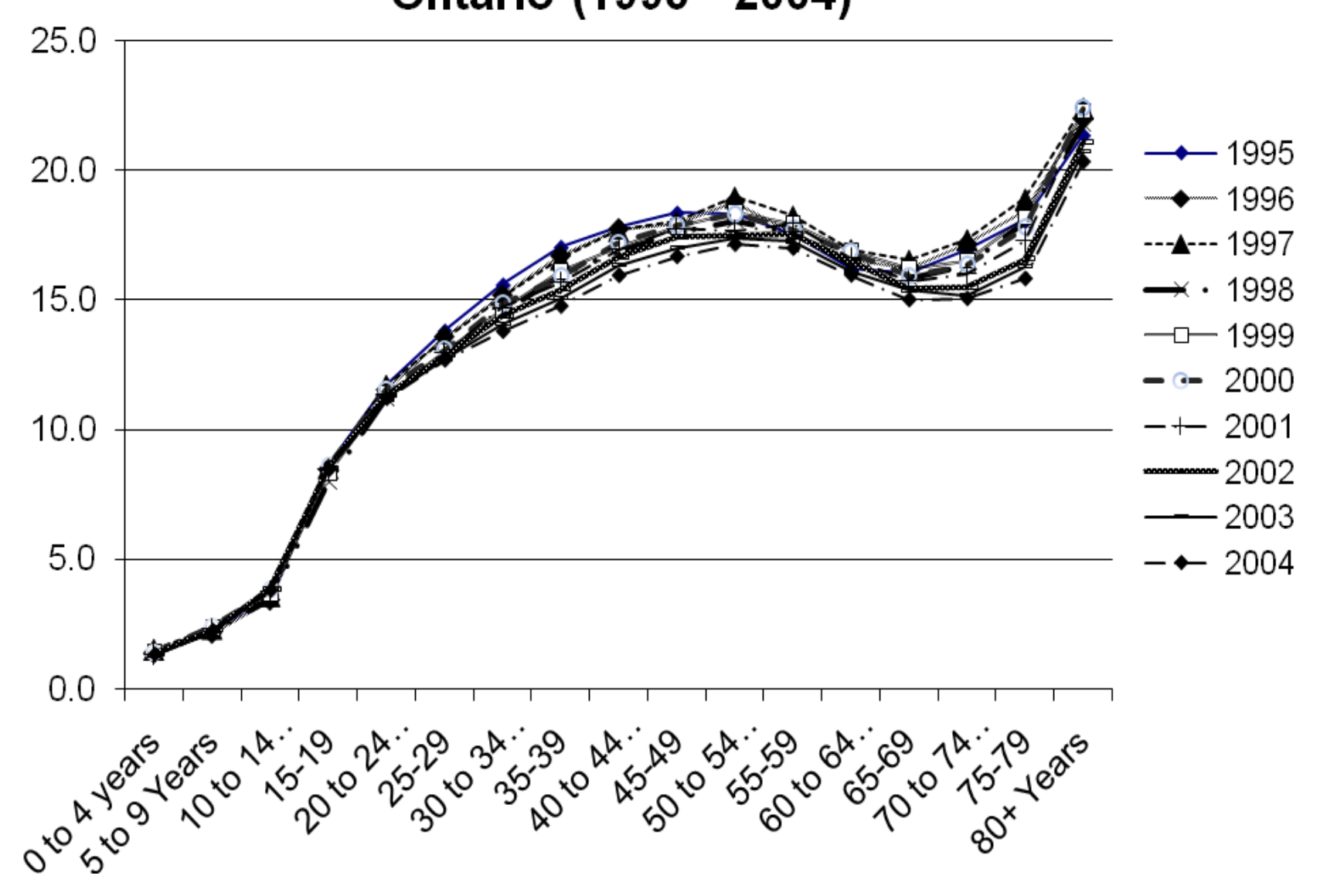

